SCIREA Journal of Computer

http://www.scirea.org/journal/Computer

December 28, 2021

Volume 6, Issue 1, February 2021

https://doi.org/10.54647/computer52247

\title{
Practice and Research of Online Teaching of High School Information Technology Binary Search
}

\author{
Huansong Yang, Songming Wu*, Ying Li \\ Hangzhou Normal University, Hangzhou, Chinese \\ Email: hzjyhs@163.com (Huansong Yang), 1150438796@qq.com (Songming Wu), \\ ly_iiisecret@163.com (Ying Li) \\ *Corresponding Author: Songming Wu
}

\begin{abstract}
Online teaching is currently a hot topic in teaching research, improving the effectiveness of online teaching is the focus of everyone's attention. Practice and research is carried out by combining teaching of high school information technology Binary search with the Dingtalk platform, discovering the use of multiple resources to build an online resource library; using resource packs; reasonably splitting online course resources into multiple stages; guiding students to use new convenient features; establish a Q\&A community to explain homework in a timely manner; methods such as comprehensive consideration of practice homework and survey methods can effectively improve students' learning effectiveness.
\end{abstract}

Keywords: DingTalk platform, High School Information Technology, Online Teaching, Practice and Research 


\section{INTRODUCTION}

Domestic and foreign research on online teaching to improve teaching effectiveness is currently a hot topic, there is still a lack of research on the combination of DingTalk platform and information technology courses to improve teaching effectiveness in many studies. In this study, the content of high school information technology Binary search combined with the DingTalk platform, conduct practical research and analysis related to numbers, come up with some strategies to improve the effectiveness of online teaching, conductive to the improvement of online teaching efficiency. It also has a certain promotion and reference significance for using other platforms for information technology online teaching to improve teaching efficiency.

\section{STRATEGIES FOR SOLVING PROBLEMS IN ONLINE TEACHING OF HIGH SCHOOL INFORMATION TECHNOLOGY}

\section{A. Basic Principles of Solution Strategy}

Before exploring the problem-solving strategy, it is necessary to put forward some basic principles for the solution strategy based on the referenced literature, broaden the thinking of the solution strategy, and also limit the errors and problems in the direction that may appear in some strategies.

\section{1) The Use of The Course Platform Should Have Three Characteristics}

For the platform that online teaching relies on, it must be functionally equipped with three characteristics: simplicity, Coherence, and systematicness. Simplicity is for the column and project design of online courses in the platform, and only with simplicity can it be easier for students to operate and log in to learn. If is too complicated and cumbersome, it will affect the students' mood and enthusiasm for learning, and even produce rebellious psychology. Coherence refers to the content of learning, the learning method, the testing of learning results, the generation of statistics and feedback, and the arrangement and design of resources and functions, such as coherent and layer-by-layer interlocking, this is conducive to the continuous learning of students, improve learning efficiency, and also facilitate students to understand the results, find problems and correct mistakes in time. systematicness includes student learning management system, teacher teaching management system, and educational administration supervision system. these systems should be fully utilized, and relevant data 
information should be fed back or notified in time to achieve the purpose of supervision and motivation [24].

\section{2) Online Teaching Resources Must Follow Four Principles}

The four principles that online teaching resources should follow are diversified resource types, visualize resource forms, interesting projects or tasks, and refined resource content. In general, while ensuring the quality of resources, it is necessary to take into account the diversification of resources as much as possible, so as to conform to the learning habits of different students, and at the same time to enable students to understand multiple levels of knowledge from different aspects and using different angles.

\section{3) Four Characteristics Should be Grasped in The Online Teaching Process}

The four characteristics that should be grasped in the online teaching process are mission, Interactivity, Exploratory, and motivation. The process design of online teaching should take task as the basic framework, and use task-driven methods to promote teaching. In the process, attention should also be paid to interaction and motivation, so that students can understand and master the knowledge at any time. For students, in the process of learning knowledge, they also need to have the spirit of inquiry. This is inseparable from the inquiry nature of online course design, so that students can find the joy of learning in inquiry, and at the same time, they can master what they have learned more efficiently.

\section{B. Specific Aspects of The Solution Strategy}

\section{1) Use Multiple Resources to Build an Online Resource Library}

Aiming at the problem of insufficient learning resources, multiple resources should be used, combined with each other to penetrate, and jointly create a good online learning environment. In this research, the author intends to add video and document resources in practice. Video resources can be watched online or watched after download. File resources can also be viewed online and downloaded, and file resources can also be edited and modified online to facilitate students to review and take notes any time during the learning process.

At the same time, these resources can be downloaded at any time. Students can download them on their computers, then watch them repeatedly or pause to take notes. In this way, the negative impact of students' weak learning experience caused by network stalls can be reduced, and it also helps students freely control their learning progress according to their 
own learning style and learning speed at any time, and can more autonomously grasp their own learning situation.

\section{2) Use The Form of Resource Pack}

The investigation and research on the online teaching situation in middle schools showed that the seven online learning methods include live broadcast, recorded broadcast, resource pack, live broadcast + recorded pack, live broadcast + resource pack, recorder broadcast + resource pack, live broadcast + recorded broadcast + resource pack. The highest student satisfaction is the resource-packed learning method, so teachers do not attend classes and only provide learning resources for students to learn by themselves. It can be seen that online learning is not necessarily the same as online classes, and there are differences between the two methods. In short-term online teaching, education departments and teachers need to trust students more, help students improve their self-learning ability, assist teaching, rather than indoctrinate [25].

Therefore, in this survey, online teaching adopts a more satisfactory form of self-study for students, but it is not completely self-study, but a certain task is added as driving and guidance, and at the same time, and at the same time, students are given the opportunity to ask questions online at any time. The teacher is more not the role of the lecturer, but the role of the instructor, allowing students to explore and learn according to the tasks arranged by the teacher, and the teacher will answer all the questions raised by the students at any time. This method not only makes students more satisfied and interested in online teaching, but also helps students give full play to their initiative and self-consciousness in learning.

\section{3) Guide Students to Use New convenient features}

Regarding the problem that the previous online teaching did not provide convenient learning functions, the author studied the various functions of the DingTalk platform itself. Teachers guide students to use various convenient functions reasonably in notifications and announcements. For example, using DingTalk's function of previewing and editing various online files at any time, it is convenient for students to view learning resources at any time, and can make online notes at any time. In terms of homework assignment, teacher can also use the function of posting homework in the DingTalk teach group to send and receive homework online, and students can also submit online and make multiple revisions. If students have questions about the knowledge learned in class or homework, they can post the questions in the learning circle provided by DingTalk, and wait for the teachers' answer. And the DingTalk platform also has functions such as schedule reminder and schedule 
arrangement. Teacher can set the schedule of learning tasks at any time. At the same time, "DING" the whole class to remind them to complete online learning tasks on time and keep up with the progress of learning.

\section{4) Reasonably Split Online Course Resources into Multiple Stages}

In the selection of resources, many online teaching resources are a whole video, and the duration is very long, which may make students feel tired, which may make students feel tried and uncomfortable. According to selected course content this time, it is divided into three stages according to the teaching objectives and the level of teaching content, which are the learning of principles, the learning of program realization, and the learning of hands-on operation. According to these stages, the learning resources are divided, the learning progress and learning tasks of each stage are determined, and the tasks are arrange in the online teaching group, so that students can study independently according to the plan.

\section{5) Establish a Q\&A Community to Explain Homework in Time}

In this online teaching practice, in response to the problems reported by the students before, the problem of untimely explanation of the homework, the function of DingTalk Learning Circle should be used to establish an online Q\&A community. Students can ask various questions about this learning in this community, such as failing to understand or thorough understanding in the process of online teaching, difficult problems in practice homework, not clear enough about specific tasks, and feedback and suggestions for the online teaching process, teachers will answer questions online in time, and at same time, students can discuss with each other and use the function of mutual comment to give their own understanding and opinions.

6) Practice Homework and Survey Methods to Comprehensively Consider Students' Learning Effects

In the final part of testing the effect of this online teaching, a combination of practice homework and surveys is used to comprehensively consider the students' online learning situation this time. The practice homework of the two methods is more objective, and it directly tests the students' mastery of various knowledge by doing questions, while the investigation methods is slightly subjective, but it can summarize the effects of practice in more detail. At the same time, specific problems were discovered. 


\section{Model Design of Solution Strategy}

Based on the detailed directions of the above various solution strategies, the author designed a set of basic models to be applied to this online teaching practice, which mainly includes the flow of the entire online teaching process and the relationship between the modules.

Before starting online teaching, learning needs to be analyzed. It is necessary to analyze the learner's situation as well as the learning content, determine the learning goal base on this, and then select the appropriate online teaching design. At the same time, the content of this online teaching is divided into three modules, which are the principle of binary search, the realization of binary search program and computer operation of binary search. In the teaching, there is a clear setting of learning tasks that require timely guidance. Through the interactive Q\&A of teaching, feedback on the teaching process can be obtained, and then timely reflection and adjustments can be made, and learning goals and learning tasks can be appropriately modified. 


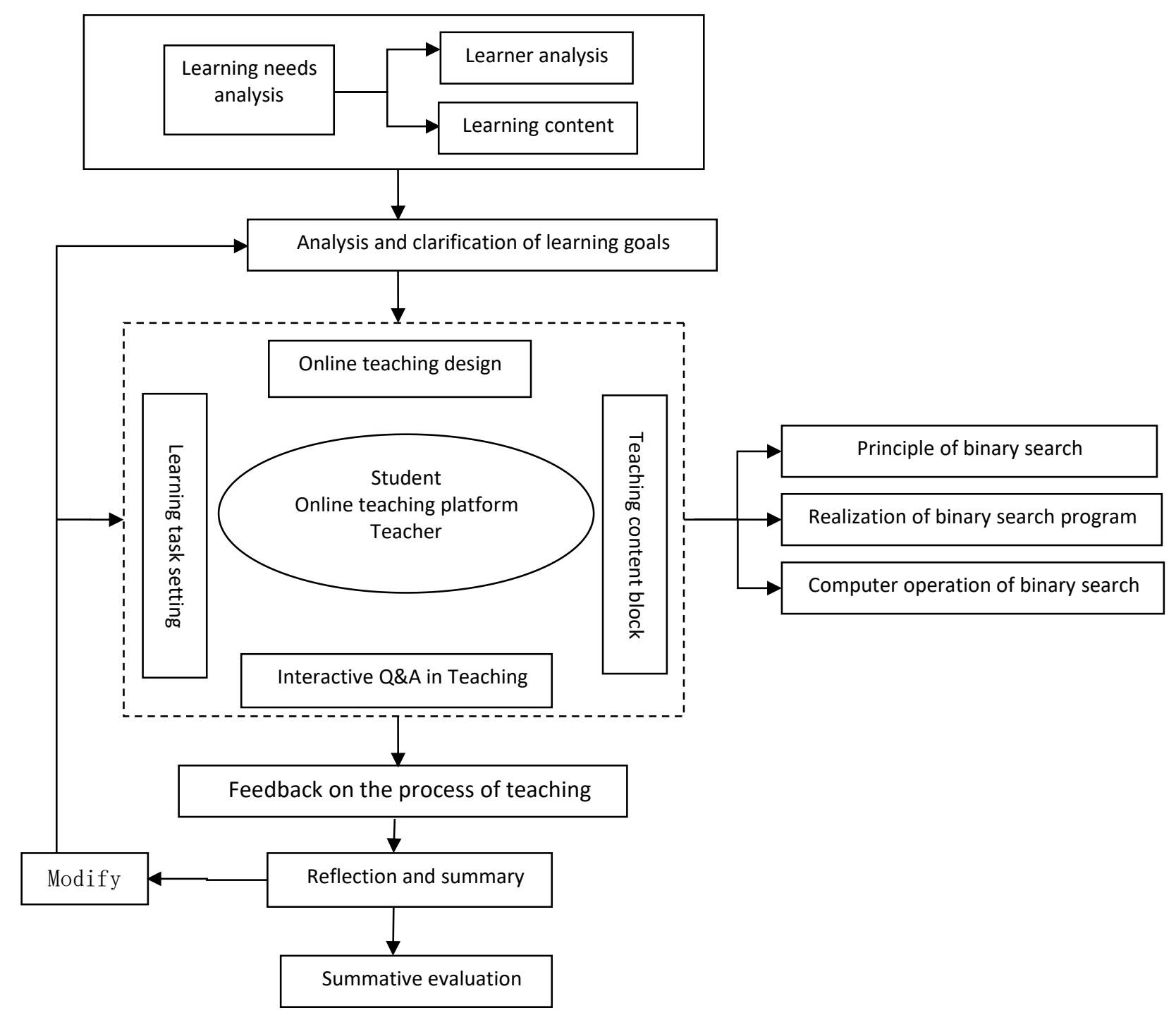

Figure 1 The model of online teaching problem of high school information technology solving strategy based on DingTalk platform

\section{III.HIGH SCHOOL INFORMATION TECHNOLOGY CONTENT BINARY SEARCH}

\section{A. Online Teaching Practice of Binary Search Principle}

The content of this class is the fourth section of Chapter Two in Algorithm and Program Design, "Binary Search", which is a new class that teaches the principle of binary search. The content of this course is the preliminary understanding and learning of the principle of binary search in the textbook. It is very theoretical and not difficult. It is reflected in the preliminary understanding and learning of the principle, and the process is strong.

New class introduction: 
[Teacher]Using the dichotomous estimation method in the mathematical function image, the new lesson content is introduced through the analogy of mathematics and information technology.

[Student]Explore the dichotomous estimation method in the mathematical function image, and have a preliminary understanding of the basic idea of binary search.

New class teaching:

Summarize the basic ideas of binary search:

[Teacher]Undertake the introduced content, discuss with students the logical relationship between mathematical and information technology, and initially introduce the binary search algorithm.

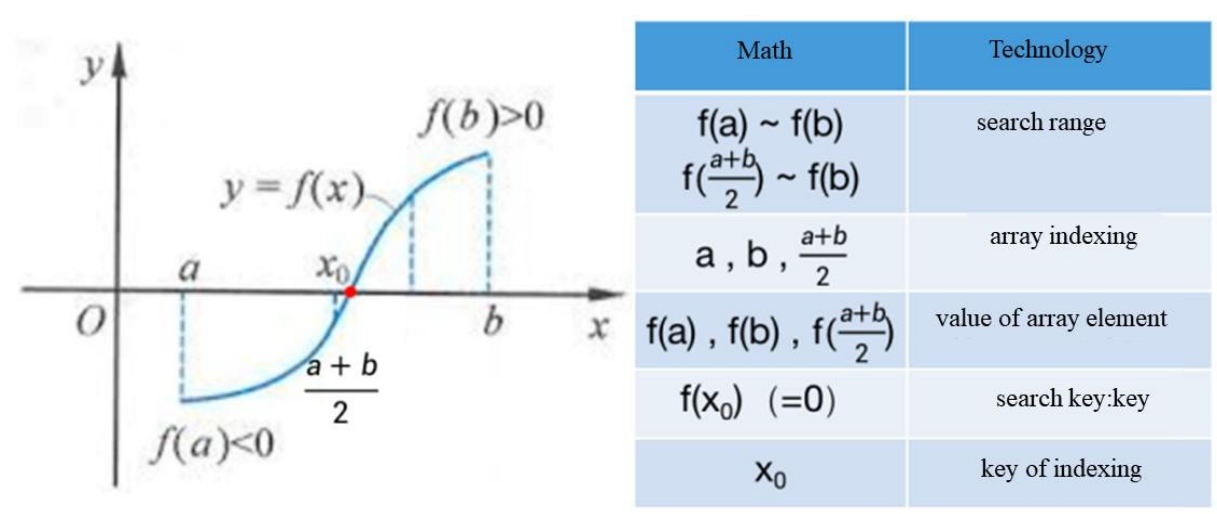

Note: Array is not a continuous function, so key is not always possible to find the corresponding value of array element,and there may not necessarily be a corresponding array indexing.

Figure 2 Summary of the introduction of courses in the online teaching practice of the principle of binary search

[Student]Contact the dichotomous estimation in the mathematical, understand the relationship of the analogy in the table.

[Design Intent] Through autonomous analogy exploration, on the one hand, students are allowed to connect with the process and ideas of the bisection method in mathematical to have a basic analogy to the idea of binary search, on the other hand, to gradually cultivate students' sense of autonomous exploration and ability to stimulate students' interest in learning.

The specific process of binary search:

Use examples to explain the specific process the binary search: 
[Teacher]Take specific data as an example to introduce the process of binary search in detail.

\section{The process of binary search(example)}

\begin{tabular}{|c|c|c|c|c|c|c|c|c|}
\hline key $=40$ & \multicolumn{4}{|c|}{ search times: } & \multicolumn{4}{|l|}{4} \\
\hline array indexing & 1 & 2 & 3 & 4 & 5 & 6 & 7 & 8 \\
\hline $\begin{array}{l}\text { value of array } \\
\text { element }\end{array}$ & 3 & 8 & 12 & 15 & 19 & 24 & 26 & 40 \\
\hline & & & & & & & & $\underset{j}{\mathrm{i}}$ \\
\hline $\begin{array}{c}\text { number of } \\
\text { comparisons }\end{array}$ & & $\begin{array}{l}\text { Scope } \\
\text { ompari }\end{array}$ & & mic & & $\begin{array}{r}\text { the } \\
\text { betw }\end{array}$ & $\begin{array}{l}\text { elatio } \\
\text { en Key }\end{array}$ & iship \\
\hline the first time & & $d(1) \sim c$ & & 4 & & & $>d(r$ & nid) \\
\hline the second time & & $d(5) \sim c$ & & 6 & & & $>d($ & nid) \\
\hline the third time & & $d(7) \sim c$ & & 7 & & & $>d($ & nid) \\
\hline the forth time & & $d(8)$ & & 8 & & & $=d(r$ & hid) \\
\hline
\end{tabular}

Figure 3 An example of the process in the online teaching practice of the principle of binary search [Design Intent] As the key content, let students understand the specific process of binary search in detail, and at the same time bring in specific data, so that students will be more intuitive, specific and detailed in understanding the whole process of binary search.

Use the binary tree method to introduce the basic process of binary search in more detail:

[Teacher]Firstly, introduce the concept of binary tree, use the concept of binary tree to introduce the entire process of binary search, and use the combination of number and shape to make the abstract thinking process gradually become concrete and direct, which is easy for students to understand.

\section{The process of binary search(example)}

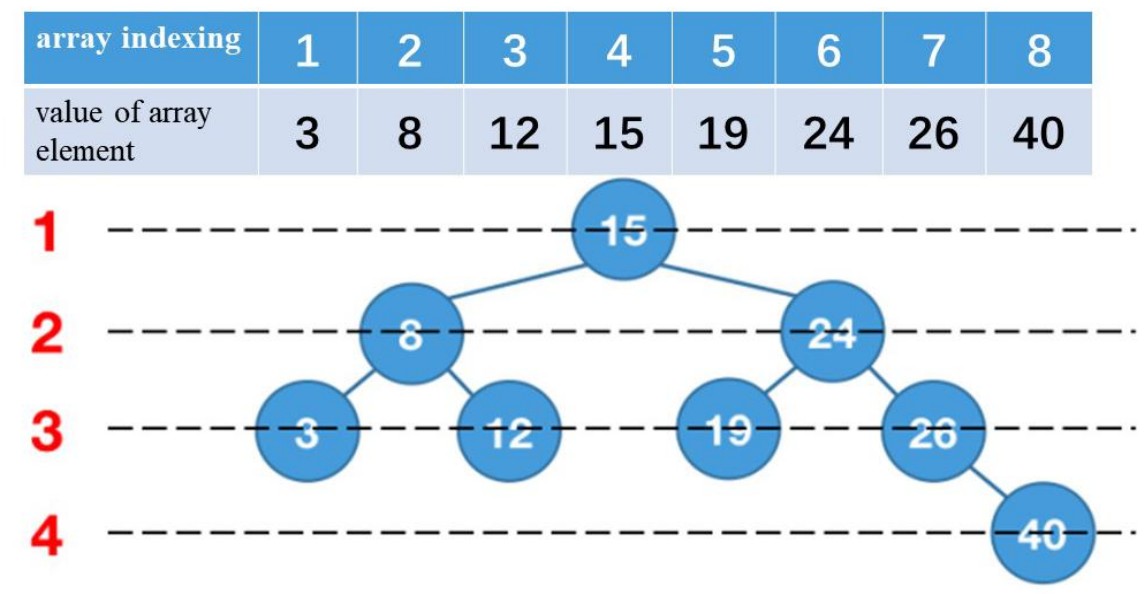

Figure 4 Binary tree diagram in the online teaching practice of the principle of binary search 
[Design Intent] Combining of lectures and exercises to help students better realize the basic process of binary search algorithm.

The efficiency of binary search:

[Teacher] Start with the binary tree and gradually summarize the law of the maximum number of binary searches. While summing up the law, use special examples to continuously perfect the law.

[Student] According to use different special examples, summarize the law of the maximum number of binary searches, and at the same time explore the efficiency of binary search in different situations and compare it with Sequential Search, and get the advantages of binary search.

\begin{tabular}{|c|c|c|c|c|c|c|c|c|}
\hline length of the array & 1 & 2 & 3 & 4 & 5 & 6 & 7 & 8 \\
\hline $\begin{array}{l}\text { maximum number } \\
\text { of searches }\end{array}$ & 1 & 2 & 2 & 3 & 3 & 3 & 3 & 4 \\
\hline length of the array & 9 & 10 & 11 & 12 & 13 & 14 & 15 & 16 \\
\hline $\begin{array}{l}\text { maximum number } \\
\text { of searches }\end{array}$ & 4 & 4 & 4 & 4 & 4 & 4 & 4 & 5 \\
\hline
\end{tabular}

Figure 5 Summary of efficiency in the online teaching practice of the principle of binary search

[Design Intent] Combining of lectures and exercises to help students better understand the efficiency of the binary search algorithm.

[Teacher] Summarize the content of this lesson by asking questions to students, and check their mastery.

[Student] According to the teacher's question, recall to the knowledge points implemented by the binary search algorithm program and answer.

[Design Intent] Guided by the teacher, students take the initiative to summarize the content learned in this lesson, further deepen the impression of the content of knowledge, cultivate students' ability to learn independently, and the ability to summarize knowledge.

Assignment: 
Complete the homework exercise for this lesson.

\section{7) Self Reflection}

It is still very clear in the specific description of the binary search process. For different examples, similar ideas are used to explain so that students can clearly understand the most important process of binary search. Finally, the method of comparison is also used to highlight the efficiency of the binary search.

\section{8) Feedback and Suggestions Based on the Process}

The introduction and specific process of the class are progressing quickly, and the rhythm is not well grasped. In the part of specific questions, students lack sufficient time for thinking.

\section{B. The Online Teaching Practice of the Binary Search Program Realize}

New class introduction:

[Teacher] In the form of exercises, guide students to sort out the knowledge point of the "principle of binary search algorithm" learned in the previous class.

[Student] Recall what they learned in the last class and summarize the principle of the binary search algorithm.

New class teaching:

Contact algorithm idea by flow chart:

[Teacher] Through the flow chart, discuss the logical relationship with students, further analyze the binary search algorithm; clarify the logical relationship of the numbers in the binary search algorithm, and have a preliminary understanding of the realization idea of the binary search algorithm. 


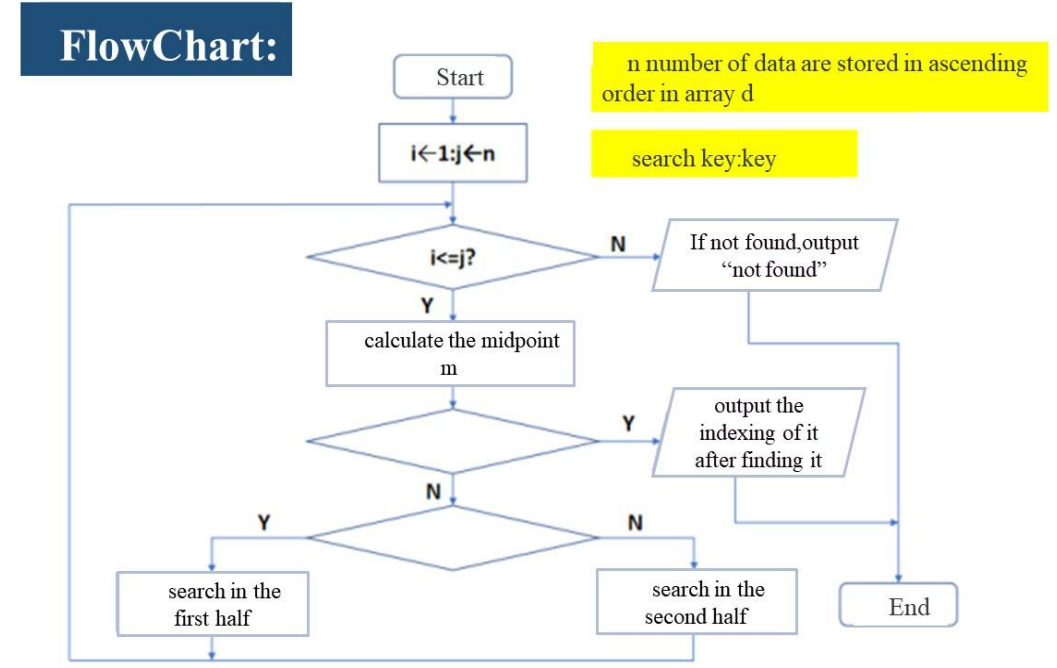

Figure 6 The flow chart of the binary search program to realize the code in the online teacher practice

[Student] Contact the principle of the algorithm and understand the logical relationship in the flow chart.

[Design Intent] Through independent experiment exploration, on the one hand, students are allowed to connect with the steps of the basic exploration program of the binary search algorithm, gradually cultivate students' awareness and ability of independent exploration, and stimulate their interest in learning.

Algorithm implenmentation:

Preface of program realization:

[Teacher] Explain some conditions and functions.

Array definition: Dim d(1 to 10) As Integer

Random number generation: $d(i)=\operatorname{int}(\operatorname{Rnd}() * 90+10)$

Key to find: Key=Val（Text1.Text）

i: index of the first array element

$\mathrm{j}$ : index of the last array element

$m=\operatorname{Fix}((i+j) / 2)$ : index of the middle position array element

fix function: delete the decimal part of $\mathrm{x}$, and directly take the integer part of $\mathrm{x}$ without rounding

val: Returns the value in the character 
[Design Intent] To deepen the impression of students and pave the way for the implementation of subsequent procedures.

Core code implementation:

[Teacher] The main code is explained, and students are guided to fill in the main code according to the flowchart. Explain the core idea: Calculate $d(m)$, compare key with $d(m)$ : Best case: $k e y=d(m)$, end the loop directly, output the position index of key, and the program ends. If $k e y \neq d(m)$, judge that key is in the front/back half of the array according to the order; the search range is reduced by half, and the elements of the $\mathrm{d}(\mathrm{m})$ array are regarded as the highest/lower bits, and the following table is set to $m-1 / m+1$, repeat the operation until the final result is obtained.

[Student] Fill in the code according to the flow chart and master the core idea of the algorithm.

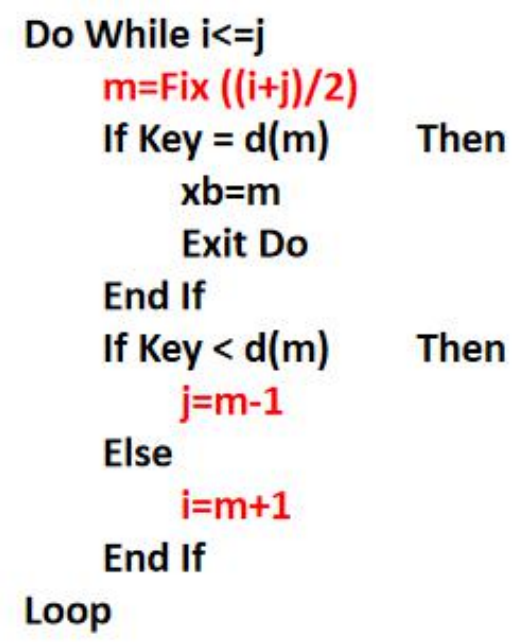

Figure 7 The binary search program realize the core code in online teaching practice

[Design Intent] Combining lectures and exercises to help students better realize the knowledge transfer from the basic idea of the binary search algorithm to the program code.

Program realization:

[Teacher] Give the complete code and sort out the logical relationship between the codes. Ask students to think about how to change the program if they want to output the number of searches?

[Design Intent] emphasize again, consolidate knowledge points, and simply modify the program, let students learn by analogy, think about the change of program code independently, and cultivate students' ability to transfer knowledge.

Program variants: 
[Teacher] Let students think about the following question:

How to change the code when outputting the number of searches?

Data flashback sorting, how to change the code?

[Student] Master the code variants according to the algorithm.

[Design Intent] Trough two variants of code changes, let students think, explore, and communicate in groups, and cultivate students' communication skills and spirit of cooperation. And can break away from the fixed mindset, find several different solutions for the same variant, and compare them to cultivate students' information literacy.

Knowledge expansion:

For an array of size $n$, the new search range will not exceed $n / 2$ through 1 search, and the new search range will not exceed $n .2^{\wedge} 2$ after 2 searches. It can be deduced that after $\mathrm{K}$ searches, The new search can be $\log 2(\mathrm{~N})+1$ times, and the binary search is more efficient.

[Design Intent] By comparing the search range and the number of searches with the sequential search algorithm, analyze which of the two algorithms is more efficient, cultivate students' ability to combine multiple aspects of knowledge, expand students' knowledge, feel the charm of different algorithms, and stimulate Interest in algorithm learning.

In conclusion:

[Teacher] Summarize the content of this lesson by asking questions to students, and check their mastery.

[Student] According to the teacher's question, recall the knowledge points implemented by the binary search algorithm program and answer.

[Design Intent] Guided by the teacher, students take the initiative to summarize the content learned in this lesson, further deepen the impression of the content of knowledge, cultivate students' ability to learn independently, and the ability to summarize and summarize knowledge.

\section{Online Teaching Practice of Binary Search and Computer Operation}

New class introduction:

[Teacher] Send the task book that needs to be completed in this lesson to the students through the online teaching group, open the task book, and explain the task book: several tasks that 
need to be completed, points that need to be paid attention to in the task process, and program code that tasks can learn from.

[Students] Watch the task book to understand the task of this lesson.

[Design Intent] Through the task book, let students have a preliminary understanding of the tasks of this class, and under the drive of the tasks, start the teaching of this class.

New class introduction:

Programming task one:

[Teacher] According to the task book, let the students complete task one within 2 minutes:

In VB, open the file "Divert Search.frm" in the folder of "Divert Search on Computer", and enter the code window after familiarizing yourself with the form interface, and then read and understand the code of the form load (form_load()) program segment and Its function causes the program to randomly generate 10 data and store them in the array a.

[Student] Analyze the problem of task one and write a code program.

[Teacher] Check the completion of students and answer questions for students who have difficulties.

Programming task two:

[Teacher] According to the task book, let students complete task two within 3 minutes:

Program the click event (command1_click()) of the button named "Generate Ordered Array" button command1, and sort the data in array a from small to large (ascending). You can use bubble sorting or selection sorting, and finally the sorted array is displayed in the list box list1 (one data is displayed in one row).

[Student] Analyze the problem of task two and write a code program.

[Teacher] Check the completion of students and answer questions for students who have difficulties.

[Teacher] According to the task book, let students complete task three within 4 minutes:

Program the click event (command1_click()) of the button named "Generate Ordered Array" button command1, and sort the data in array a from small to large (ascending). You can use bubble sorting or selection sorting, and finally the sorted array is displayed in the list box list 1 (one data is displayed in one row). 
[Student] Analyze the problem of task two and write a code program.

[Teacher] Check the completion of students and answer questions for students who have difficulties.

Programming task four:

[Teacher] According to the task book, let students complete the three variants of task four within 20 minutes:

Realize binary search in descending order.

[Student] Analyze the problem and write a code program.

[Teacher] Check the completion of students and answer questions for students who have difficulties.

Realize the use of marked variables to control the end of the loop.

[Student] Analyze the problem and write a code program.

[Teacher] Check the completion of students and answer questions for students who have difficulties.

Consider how to round up mid when searching for data, think about and observe the changes in the search process.

[Student] Analyze the problem and write a code program.

[Teacher] Check the completion of students and answer questions for students who have difficulties.

Programming task five:

[Teacher] Let students save and upload the program regardless of the degree of completion of the tasks in this lesson during the remaining time.

[Student] Save and upload the program.

[Design Intent] Let students start with simple programs, consolidate their knowledge of algorithms, and stimulate their interest in learning this lesson. Several variations are given to allow students to discuss with each other and learn from each other, so that students can experience the methods of scientific inquiry, thereby cultivating students' scientific attitude and the spirit of actively exploring knowledge.

In conclusion: 
[Teacher] Summarize the problems that students have encountered in the process of writing code, and analyze the reasons for the problems with students and how to avoid them next time.

[Design Intent] Throw out all the problems encountered by the students, and guide them to discuss the causes of errors and solutions, so that students can consolidate their knowledge while also gaining new ideas for solving problems from other students. At the same time, it also stimulates students' interest in learning information technology courses, and promotes students to learn and progress together.

\section{Practice Effectiveness Analysis}

Questionnaires were distributed to 81 students who participated in the experiment and summarized as follows:

\section{1) The Biggest Improvement in Practice is That Students can Watch the Replay in Time}

Through the questionnaire survey, it is found that students believe that the biggest improvement in this practice is that they can watch the playback in time or find knowledge points that they did not understand. Followed by more convenient learning methods, it has become the second major improvement area. Students can learn and save online resources in time, and they can also take online notes in time, which greatly improves the fun of online learning for students. It also brings them a better sense of experience.

\section{2) Over Half of the Students Think the Learning Goals are Very Clear}

In all the questionnaires returned, more than half of the students believed that the learning goals of this online teaching were clearer than usual. This is due to the fact that teachers can publish learning tasks to students in a timely manner on the DingTalk platform, and clearly inform students of their learning goals through announcements and other methods. In the learning process, students are also divided into different chapters and levels to learn. This way makes students feel the clarity of their learning goals, and can also improve their learning efficiency and effect.

\section{3) Most Students Think the Learning Content is More Deeper}

In all the questionnaires, more than $44 \%$ of students believe that the content of this online teaching is deeper than usual, which is reflected in the interpretation of knowledge with more angles and levels. This allows students to have more understanding methods when facing knowledge learning, and the content naturally appears deeper. 
Nearly $40 \%$ of the students believe that the online teaching process is basically clearer than usual, accounting for the largest proportion of the total number of students. In addition, more than $44 \%$ of students believe that the online teaching process is clearer than usual. This kind of students prefer the online teaching model and experience. They can experience the fun in the online teaching process, and at the same time can keep up with the teacher's course schedule and progress, and show greater interest and better in online teaching.

\section{5) The Overall Results of the Online Practice Assignments are Relatively Good}

Based on the comprehensive consideration of data analysis and conversation, students' online homework scores are generally good. More than $90 \%$ of the students can get a pass or higher in the objective evaluation, and more than $50 \%$ of the students can get good or above in the final test, but there are still students whose scores are not ideal. Through the conversation, it was learned that the students with unideal grades were basically due to the following two types of reasons. There are two reasons. One is because this class is a weekend study, they did not pay much attention to and participated in the online learning, so there were corresponding obstacles and problems in the study and final grades. The second is that online learning has strong self-consciousness and autonomy. Although teachers will regularly check and supervise students' progress and completion, part of the final learning effect still requires students to actively participate in the construction. Even so, these problems are still a minority phenomenon after all. Overall, the students' objective evaluation of the effect of online learning is relatively good.

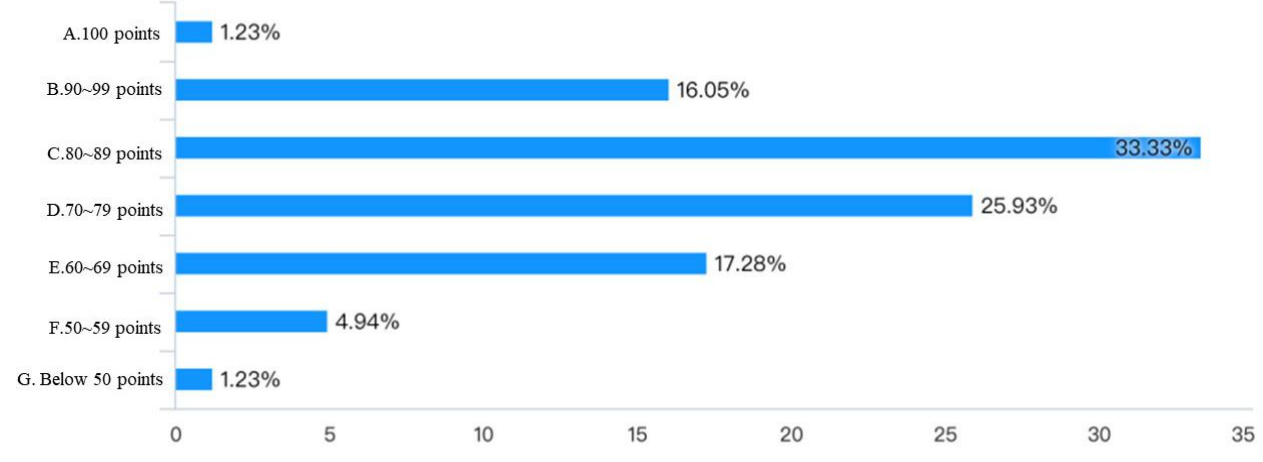

Figure 8 Statistics on the overall performance of students' online homework

\section{6) Online Teaching Has Cultivated Students' New Study Habits}

Through this online teaching, students have developed many new good habits, and the largest number of students have developed the habit of taking online notes in time. Through the 
guidance and task arrangement of teachers, they can also review the knowledge learned in a timely manner. Such students are more active and active in the online learning process, and the learning effect is better. At the same time, there are many other new good habits, such as communicating their problems and difficulties with teachers in a timely manner through the network platform, so that students can get timely responses and solutions from teachers, and they will also increase their enthusiasm. At the same time, responding to the needs of students in a timely manner can also stimulate and promote students' continued learning in the next stage.

\section{7) More Than 60\% of Students Believe That They Have Learned More Online Than Usual}

More than $60 \%$ of students believe that online teaching can learn more knowledge than usual. Through conversation, this is mostly due to the widespread use of the Internet, which allows students to learn more abundant and broad knowledge through the Internet, and also benefits from the rich and high-quality online teaching resources. Therefore, in the selection and combination of online teaching resources in the future, it is necessary to use more abundant and high-quality online teaching resources, which can improve the learning effect and learning experience of students.

\section{IV.CONCLUDING REMARKS}

DingTalk platform is an effective online teaching platform, and by using this platform, combining relevant subjects for effective online teaching is our goal. Through the practical research of combining the content of high school information technology binary search with the DingTalk platform, the strategic model and related solution strategies established by it to solve teaching problems are an effective solution, and it has been proven in practice. This solution also has good reference value for teaching other subjects.

\section{REFERENCES}

[1] Y. Tan, "Basic Features and Implementantion Strategies of Blended Teaching Mode", Chinese Vocational and Technical Education,no.32, pp.5-9,2018.

[2] X. Ding, "New Definitions of Distance Education, Distance Teaching and Distance Learning-Discussion on the Basic Concepts of Distance Education and Open Learning”, China Educational Technology,no.07, pp.47-49,2000. 
[3] G. Wang, "Analysis on the Application of Micro-courses in High School Information Technology Teaching”, China Modern Educational Equipment,no.31, pp.94-95,2013.

[4] W. Li, "The Cultivation of Core Quality in the Teaching of Information Technology Subjects in General Senior High Schools", China Educational Technology,no.05, pp.26$29,2017$.

[5] M. Jiang, S Yan, "Research on Online Teaching Practice Based on "You MOOC Platform + DingTalk Live Broadcast"”, China Modern Educational Equipment,no.09, pp.13-15,2020. 